\title{
RNA interference-mediated knockdown of Livin suppresses cell proliferation and invasion and enhances the chemosensitivity to cisplatin in human osteosarcoma cells
}

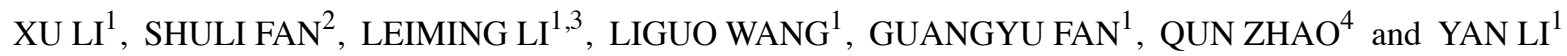 \\ Departments of ${ }^{1}$ Orthopaedic Surgery and ${ }^{2}$ Geriatrics, The First Affiliated Hospital of China Medical University, \\ Shenyang, Liaoning 110001; ${ }^{3}$ Department of Orthopaedic Surgery, The General Hospital of Benxi Steel Group Corporation, \\ Benxi, Liaoning 117000; ${ }^{4}$ Key Laboratory of Health Ministry for Congenital Malformation, Shengjing Hospital, \\ China Medical University, Shenyang, Liaoning 110004, P.R. China
}

Received February 4, 2013; Accepted April 12, 2013

DOI: 10.3892/ijo.2013.1925

\begin{abstract}
Livin is a novel member of the inhibitor of apoptosis protein (IAP) family that has been reported to be overexpressed in a variety of human malignancies, including osteosarcoma. However, the potential roles of Livin in tumorigenesis have not been elucidated. In the present study, we employed RNA interference (RNAi) technology to suppress endogenous Livin expression in osteosarcoma cells and successfully generated a U2-OS cell line with stably knockdown of Livin. Functional analysis showed that knockdown of Livin significantly reduced cell proliferation, colony formation, and invasion and migration capacities of U2-OS cells in vitro. Moreover, specific downregulation of Livin led to cell cycle arrest at the G0/G1 phase and eventual apoptosis. Meanwhile, western blot analysis revealed that cells with stably knockdown of Livin showed decreased expression levels of Cyclin D1, Bcl-2, matrix metalloproteinase (MMP)-2 and MMP-9, but increased expression levels of activated Caspase-3, Bax and cleaved poly (ADP-ribose) polymerase (PARP) compared to those transfected with a control vector. We also observed that suppression of Livin expression in osteosarcoma cells increased their chemosensitivity to cisplatin. Taken together, our data suggest that Livin is involved in tumorigenesis of human osteosarcoma and may serve as a promising therapeutic target for osteosarcoma.
\end{abstract}

Correspondence to: Dr Yan Li, Department of Orthopaedic Surgery, The First Affiliated Hospital of China Medical University, 155 North Nanjing Street, Shenyang, Liaoning Province 110001, P.R. China E-mail: cmulhliyan@163.com

Dr Qun Zhao, Key Laboratory of Health Ministry for Congenital Malformation, Shengjing Hospital, China Medical University, 36 Sanhao Street, Shenyang, Liaoning Province 110004, P.R. China E-mail: cmu2hzhaoqun@163.com

Key words: Livin, osteosarcoma, RNA interference, proliferation, invasion, chemosensitivity

\section{Introduction}

Osteosarcoma is the most frequently diagnosed primary malignant bone tumor in children and adolescents, accounting for an estimated $2.4 \%$ of all malignancies in pediatric patients (1). The overall 5-year survival rate for osteosarcoma patients has improved from less than $20 \%$ in the early 1960 s to around $70 \%$ by the mid-1980s, largely as a consequence of advances in medical treatments (i.e., chemotherapy and limb salvage surgery) (2). However, there have been no continuous improvements over the past twenty years, and the 5-year survival rate for patients with the metastatic disease remains approximately $20 \%(3,4)$. Therefore, the identification of key regulators that govern progression and malignant behavior of osteosarcoma may provide insights into the development of novel therapeutic strategies for this malignancy.

Livin [also known as melanoma inhibitor of apoptosis protein (ML-IAP) or kidney inhibitor of apoptosis protein (KIAP)] belongs to the inhibitor of apoptosis protein (IAP) family that also includes C-IAP1, C-IAP2, NAIP, Survivin, $\mathrm{X}$-linked IAP (XIAP), Bruce and IAP-like protein (ILP)-2 $(5,6)$. Similar to other IAP family members, Livin binds directly to certain caspases via its baculoviral IAP repeat (BIR) domain and subsequently initiates their inactivation and degradation, thereby inhibiting cellular apoptosis (7-9). Several studies have documented that Livin mRNA and protein are undetectable in most adult human tissues, but are abundantly expressed in diversified types of human tumor tissues, including bladder cancer $(10,11)$, non-small cell lung cancer (NSCLC) (12), nasopharyngeal carcinoma (13), renal cell carcinoma (14), hepatocellular carcinoma (15), neuroblastoma (16), colorectal cancer (17), melanoma (18) and gastric cancer (19). In addition, a series of functional studies have demonstrated that knockdown of Livin by RNA interference (RNAi) inhibits proliferation and invasion, promotes apoptosis and increases chemosensitivity in cancer cells (20-28). These findings highlight Livin as a promising therapeutic target for cancer prevention and treatment (6). Recently, Nedelcu et al have reported that Livin is frequently overexpressed in osteosarcoma, and overexpression of Livin 
is associated with poor patient survival (29). To our knowledge, however, the functional role of Livin in osteosarcoma remains to be elucidated.

In the present study, we used an RNAi-based approach specifically targeting Livin mRNA to investigate how stable depletion of Livin affects the malignant phenotypes of human osteosarcoma cells. We report that suppression of endogenous Livin levels in human osteosarcoma cells decreased cell proliferation, migration and invasion, and also increased chemosensitivity. Our data suggest that Livin contributes the aggressive behavior of osteosarcoma and may serve as a potential target for osteosarcoma therapy.

\section{Materials and methods}

Cell culture. The human osteosarcoma cell lines MG-63, U2-OS and Saos-2 were obtained from the American Type Culture Collection (ATCC, Rockville, MD, USA) and cultured in Dulbecco's modified Eagle's medium (DMEM, Gibco, Grand Island, NY, USA) containing 10\% heat-inactivated fetal bovine serum (FBS, Hyclone, Logan, UT, USA), $2 \mathrm{mM}$ L-glutamine, $100 \mathrm{U} / \mathrm{ml}$ penicillin, and $100 \mu \mathrm{g} / \mathrm{ml}$ streptomycin at $37^{\circ} \mathrm{C}$ in a humidified atmosphere of $5 \% \mathrm{CO}_{2}$ and 95\% air. For passaging, all cells were periodically detached with $0.25 \%$ trypsin-ethylene diamine tetraacetic acid solution and subsequently replated. Cells in the logarithmic phase of growth were used for the experiments.

Plasmid construction. The pGCsi-H1 plasmid (GeneChem, Shanghai, China) was used to generate short hairpin RNA (shRNA) specific for Livin. A pair of DNA template oligonucleotides encoding the target sequence of Livin mRNA (GeneBank accession: NM_022161.2) was designed and chemically synthesized as follows: sense, 5'-GATCCCCAGTG GTTCCCCAGCTGTCATTCAAGAGATGACAGCTGGGG AACCACTTTTTT-3'; antisense, 5'-AGCTAAAAAAGTGGTT CCCCAGCTGTCATCTCTTGAATGACAGCTGGGAACCA CTGGG-3'. The italic sequences indicate insert sequences targeting Livin mRNA (519-537 bp). These oligonucleotides were annealed and subcloned into the HindIII and BamHI sites of the pGCsi-H1 vector. Scrambled shRNA sequence with minimal homology to known mammalian genes was used as a negative control. The accuracy of the recombinant vectors was confirmed by restriction enzyme analysis and sequencing.

Transfection and selection for stable transfectants. For transfection, U2-OS cells were seeded into 6-well plates at a density of $1.0 \times 10^{5}$ per well and allowed overnight growth to reach $70-80 \%$ confluence. Cells were then transfected with pGCsi-H1-Livin shRNA or control plasmid using Lipofectamine 2000 (Invitrogen, Carlsbad, CA, USA) according to the supplier's protocol. At $48 \mathrm{~h}$ post-transfection, stable cell clones were obtained by Geneticin (G418, $800 \mu \mathrm{g} / \mathrm{ml}$, Invitrogen) selection for 4 weeks. The individual G418-resistant clones were picked, identified for Livin expression, and maintained in medium containing $350 \mu \mathrm{g} / \mathrm{ml} \mathrm{G} 418$ for further experiments.

Quantitative real-time PCR. Total RNA was isolated from treated cells with TRIzol reagent (Invitrogen) and reverse-tran- scribed to synthesize cDNA using the PrimeScript 1st Strand cDNA Synthesis Kit (Takara, Dalian, China) according to the manufacturer's instructions. cDNA was subsequently amplified by SYBR-Green based real-time PCR on an Exicycler ${ }^{\mathrm{TM}} 96$ thermal block (Bioneer, Daejeon, Korea) using the following primers:Livin,forward,5'-GTCAGTTCCTGCTCCGGTCAA-3'; reverse, 5'-GGCTGCGTCTTCCGGTTCTT-3'; $\beta$-actin, forward, 5'-CTTAGTTGCGTTACACCCTTTCTTG-3'; reverse, 5'-CTG TCACCTTCACCGTTCCAGTTT-3'. After $10 \mathrm{~min}$ at $95^{\circ} \mathrm{C}$ to activate DNA polymerase, the cycling parameters were as follows: 40 cycles consisting of denaturation at $95^{\circ} \mathrm{C}$ for $5 \mathrm{sec}$, annealing at $60^{\circ} \mathrm{C}$ for $30 \mathrm{sec}$, and extension at $72^{\circ} \mathrm{C}$ for $30 \mathrm{sec}$. Primer specificity was confirmed by melting curve analysis. Livin mRNA expression levels were calculated by the comparative cycle threshold $(\mathrm{Ct})$ method using $\beta$-actin as an internal reference for normalization (30).

Western blot analysis. Western blot analysis was performed using whole cell lysates, separated on sodium dodecyl sulfate polyacrylamide gel electrophoresis (SDS-PAGE), and electrotransferred onto polyvinylidene fluoride (PVDF) membranes (Millipore, Bedford, MA, USA) as described previously (31). The membranes were immunoblotted overnight at $4^{\circ} \mathrm{C}$ with rabbit polyclonal to Livin (1:500 diluted, ab97350), rabbit polyclonal to Bcl-2 (1:1,000 diluted, ab18210), rabbit polyclonal to Bax (1:1,000 diluted, ab7977), rabbit polyclonal to active Caspase-3 (1:200 diluted, ab2302), rabbit polyclonal to cleaved poly (ADP-ribose) polymerase (PARP) (1:1,000 diluted, ab4830), rabbit polyclonal to Cyclin D1 (1:200 diluted, ab95281), rabbit polyclonal to matrix metalloproteinase-2 (MMP-2) (1:500 diluted, ab53771), rabbit polyclonal to MMP-9 (1:1,000 diluted, ab38898) (all from Abcam, Cambridge, MA, USA), and mouse monoclonal to $\beta$-actin (1:5,000 diluted, Sigma-Aldrich, St. Louis, MO, USA). The membranes were then developed with horseradish peroxidase-labeled anti-mouse or anti-rabbit IgG by chemiluminescence substrate (Millipore). Protein expression levels were quantified by densitometric analysis.

Colony formation assay. The tested cells were seeded at $2 \times 10^{2}$ cells per $10 \mathrm{~mm}$ dish and incubated at $37^{\circ} \mathrm{C}$ for $10-14$ days to allow colonies to form. The cell colonies were washed twice with phosphate-buffered saline (PBS), fixed with methanol, and stained with Giemsa staining solution. Visible colonies were counted manually.

Cell proliferation assay. Cell viability was evaluated by colorimetric assay using 3-(4,5-dimethylthiazol-2-yl)-2, 5-diphenyltetrazolium bromide (MTT). Briefly, cells were seeded into 96-well plates at a density of $5 \times 10^{3}$ and allowed to adhere. After incubation for various time intervals, cells were stained with $100 \mu \mathrm{l}$ sterile MTT dye $(0.5 \mathrm{mg} / \mathrm{ml}$, Sigma-Aldrich) for $4 \mathrm{~h}$ at $37^{\circ} \mathrm{C}$. Then, the supernatant was removed, and the resultant formazan crystals were dissolved in dimethyl sulfoxide (DMSO, Sigma-Aldrich). The absorbance value was read at $570 \mathrm{~nm}$ using a microplate reader.

Hoechst 33258 staining. The nuclear changes and apoptotic body formation were visualized with Hoechst 33258 staining. Cells were fixed with $4 \%$ paraformaldehyde at $4^{\circ} \mathrm{C}$ 
for $20 \mathrm{~min}$, washed with PBS, and incubated with Hoechst 33258 (Beyotime Institute of Biotechnology, Haimen, China) at room temperature for $30 \mathrm{~min}$. Finally, cells were mounted and examined by fluorescence microscopy.

Apoptosis and cell cycle analysis by flow cytometry. For cell cycle analysis, cells were detached by trypsin digestion, fixed with ice-cold $70 \%$ ethanol overnight, and stained with $50 \mu \mathrm{g} / \mathrm{ml}$ propidium iodide (PI) in the presence of RNase A at $37^{\circ} \mathrm{C}$ for $30 \mathrm{~min}$. Intracellular DNA content was analyzed using a FACSCalibur flow cytometer (BD Biosciences, San Jose, CA, USA).

Apoptotic cells were quantified by flow cytometry using an Annexin V-FITC/PI Apoptosis Detection Kit (KeyGen Biotech, Nanjing, China) according to the manufacturer's instructions. In brief, subconfluent culture of U2-OS cells or cells treated with $10 \mu \mathrm{g} / \mathrm{ml}$ cisplatin (Meilun Biotechnology, Dalian, China) for $24 \mathrm{~h}$ were harvested by trypsinization, washed with ice-cold PBS, and incubated with $500 \mu 1$ of the Annexin V-binding buffer. Thereafter, the samples were stained with $5 \mu 1$ of fluorescein isothiocyanate (FITC)-labeled Annexin $\mathrm{V}$ and $5 \mu \mathrm{l}$ of PI at room temperature for $15 \mathrm{~min}$ in the dark before analysis by flow cytometry.

Wound healing assay. Cells were subcultured in 6-well plates at a density of $5 \times 10^{5}$ cells/well and allowed to form a confluent monolayer. After removal of the culture medium, cell monolayers were gently scratched with a $200-\mu 1$ pipette tip to create a linear wound. The wounded monolayers were washed twice with serum-free medium to remove cell debris, and cells were then allowed to migrate into the cell-free area. The scratch area was photographed immediately and at 12 and $24 \mathrm{~h}$ after scratching. Cell migration was calculated as the mean percentage of the cell migrated distance compared with the initial wound distance.

Matrigel invasion assay. Invasion of U2-OS cells was assessed using Transwell cell culture chambers $(8 \mu \mathrm{m}$ pore size, Costar, Cambridge, MA, USA) containing a Matrigel-coated polycarbonate membrane filter. The upper surface of the filter was coated with Matrigel (1 mg/ml, BD Biosciences). Cells $\left(1 \times 10^{4}\right.$ cells/well) in $500 \mu 1$ of serum-free medium were placed in the upper chamber of the Transwell insert, and the lower chamber was filled with $750 \mu \mathrm{l}$ culture medium with $10 \%$ FBS (chemoattractant). After incubation at $37^{\circ} \mathrm{C}$ for $24 \mathrm{~h}$, non-invasive cells on the upper surface of the filter were removed using a cotton swab, and the invasive cells on the bottom side of the membrane were fixed with formaldehyde and stained with hematoxylin. The number of cells was counted under the microscope from six random fields at a x200 magnification.

Statistical analysis. All experiments were repeated in triplicate and data are expressed as mean \pm standard deviation (SD). Statistical differences between groups were evaluated by one-way analysis of variance, and the Bonferroni post hoc test was used for multiple comparisons. Graphs were plotted and statistical calculations were performed using SigmaPlot 12.0 (Systat Software Inc., San Jose, CA, USA). A P-value of $<0.05$ was considered statistically significant.

\section{Results}

Stable knockdown of Livin by plasmid-mediated shRNA in $U 2-O S$ cells. We first examined the expression of Livin protein by western blot analysis in several osteosarcoma cell lines (MG-63, U2-OS and Saos-2). As shown in Fig. 1A, relative high expression of Livin protein was observed in all analyzed cell lines. To further characterize the biological role of Livin in osteosarcoma, we employed an RNAi approach to knockdown Livin expression in U2-OS cells expressing the highest level of endogenous Livin. Stable transformants were obtained by G418 selection and identified by quantitative real-time PCR and western blot analysis. The results showed that the Livin mRNA and protein levels in cells transfected with specific shRNA for Livin were significantly reduced by 70 and $73 \%$, respectively, compared with those transfected with control shRNA $(\mathrm{P}<0.01$, Fig. 1B and $\mathrm{C})$. Thus, the specific shRNA targeting Livin mRNA could effectively knockdown Livin expression at both transcriptional and translational levels.

Stable knockdown of Livin expression decreased cell proliferation and in vitro tumorigenic potential of U2-OS cells. Next, we evaluated the effects of shRNA-mediated stable knockdown of Livin expression on anchorage-independent growth by the colony formation assay. Compared with U2-OS cells expressing control shRNA, U2-OS cells with Livin knockdown produced fewer and smaller colonies, suggesting a reduced in vitro tumorigenic potential ( $\mathrm{P}<0.01$, Fig. $2 \mathrm{~A})$. In addition, the effects of Livin knockdown on cell proliferation was also assessed by the MTT assay. As illustrated in Fig. 2B, suppression of Livin resulted in a significant decrease in the proliferation rate of U2-OS cells at 48, 72 and $96 \mathrm{~h}(\mathrm{P}<0.01)$. Together, our data indicate that Livin contributes to cell proliferation and in vitro tumorigenic potential of U2-OS cells.

Stable knockdown of Livin expression induced apoptosis and cell cycle G1-S phase arrest in U2-OS cells in vitro. To explore the possible mechanisms underlying the actions of Livin on the growth of U2-OS cells, we evaluated the cell cycle distribution in Livin shRNA transfected cells and control cells by using flow cytometry analysis. Fig. 3A shows that Livin depletion in U2-OS cells caused an accumulation of cells in the G0/G1 phase and a decrease in the $\mathrm{S}$ phase and G2/M phase as compared with control shRNA transfected cells. Consistently, a significant decreased level of cyclin D1 was detected in Livin shRNA transfected cells ( $\mathrm{P}<0.01$, Fig. 3B). These data suggest that downregulation of Livin arrests cell cycle at the G0/G1 phase, thereby regulating osteosarcoma cell growth.

Hoechst nuclear staining and flow cytometry analysis were undertaken to investigate the effects of Livin shRNA on apoptosis in vitro. Representative photographs of cells stained with Hoechstare shown in Fig. 4A. The formation of typical apoptotic bodies was observed in U2-OS cells with knockdown of Livin, but not in the control cells. Results from Annexin V-FITC/PI analysis also revealed that U2-OS cells transfected with Livin shRNA $(31.86 \pm 8.16 \%)$ underwent obvious apoptosis than control shRNA transfected cells $(4.34 \pm 1.55 \%)$ and untransfected cells $(4.83 \pm 1.15 \%$, Fig. 4B). We also analyzed protein expression levels of several apoptosis-associated factors by western blot analysis. Compared with control cells, the protein 
A
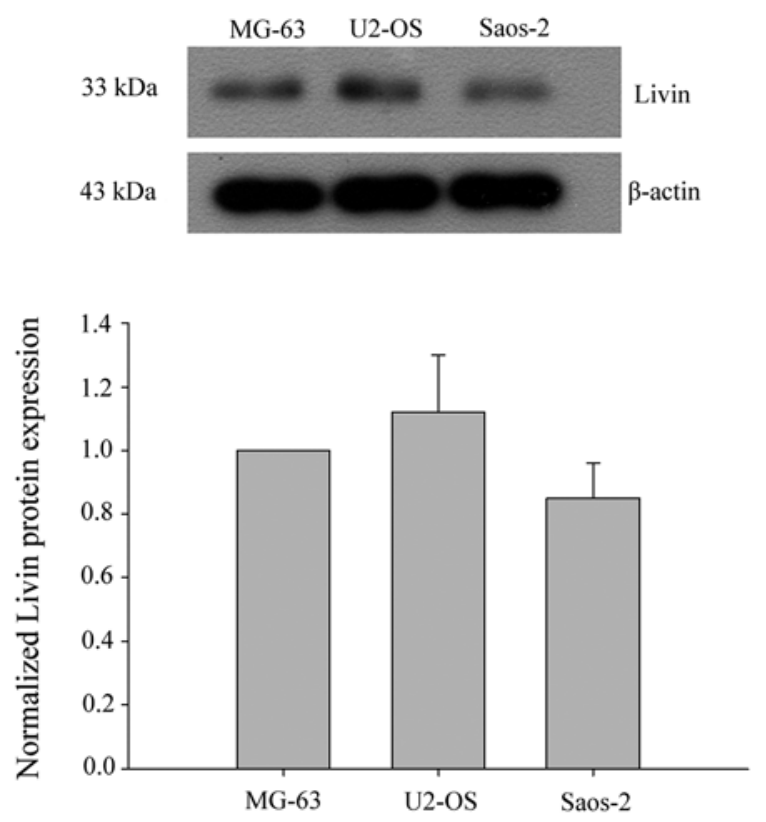

C
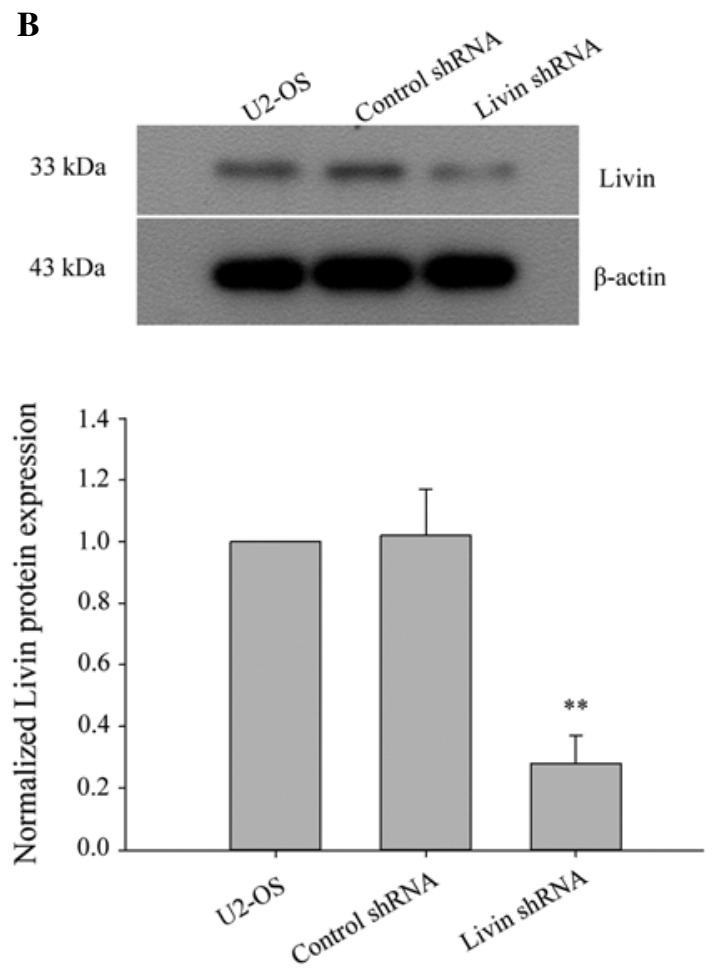

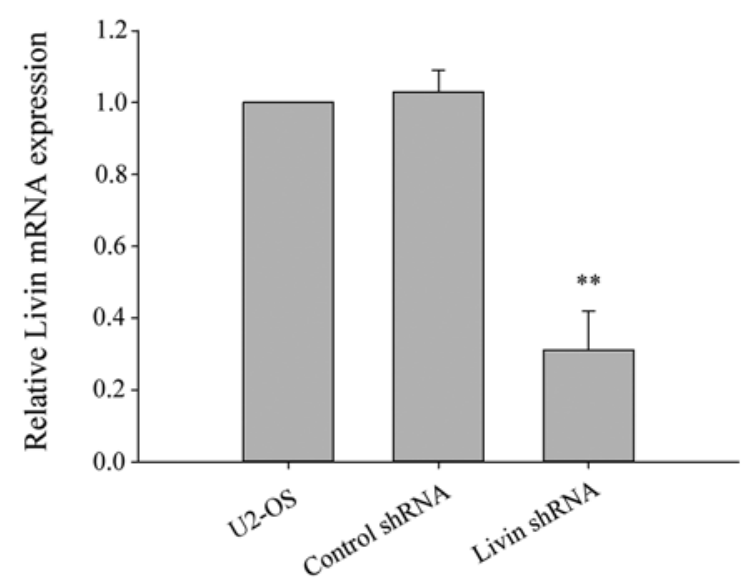

Figure 1. shRNA-mediated inhibition of Livin protein expression in osteosarcoma cells. (A) Western blot analysis of Livin in a panel of osteosarcoma cell lines. Specific gene silencing of Livin appeared in shRNA-transfected U2-OS cells by (B) western blot analysis and (C) quantitative real-time PCR. Representative blots are shown and protein size is expressed in $\mathrm{kDa}$. $\beta$-actin was used as a loading control. Data are expressed as means $\pm \mathrm{SD}$. ${ }^{* *} \mathrm{P}<0.01 \mathrm{compared}$ with control shRNA cells.

expression levels of activate Caspase-3, Bax and cleaved PARP were significantly increased, whereas the expression level of Bcl-2 was remarkably reduced in Livin shRNA transfected U2-OS cells ( $\mathrm{P}<0.05$, Fig. 4C). Collectively, our observations suggest that suppression of cell growth by Livin shRNA is partially attributable to increased apoptosis in vitro.

Stable knockdown of Livin expression inhibited migration and invasion capacity of U2-OS cells in vitro. Livin has been shown to be required for migration and invasion of several types of cancer cells $(25,27,32)$. Therefore, we determined the effects of Livin depletion on migration and invasion ability of U2-OS cells using the wound healing assay and the Transwell invasion assay, respectively. As shown in Fig. 5A, the wound healing capacity was obviously reduced in stably Livin knockdown cells as compared with control cells. Moreover, the Transwell invasion assay showed that Livin depletion significantly suppressed invasion of U2-OS cells in vitro, as evidenced by a significant decrease in the number of cells that invaded through the Matrigel-coated membrane $(\mathrm{P}<0.05$, Fig. 5B). To investigate the mechanism responsible for the reduced migration and invasion ability caused by downregulation of Livin, we quantified the protein expression levels of MMP-2 and MMP-9 by western blot analysis. In comparison to U2-OS cells and control shRNA transfected cells, MMP-2 and MMP-9 protein levels were significantly reduced in stably Livin knockdown cells $(\mathrm{P}<0.01$, Fig. 5C). Altogether, the results imply that knockdown of Livin reduces the metastatic ability of osteosarcoma cells by downregulating MMP-2 and MMP-9. 
A
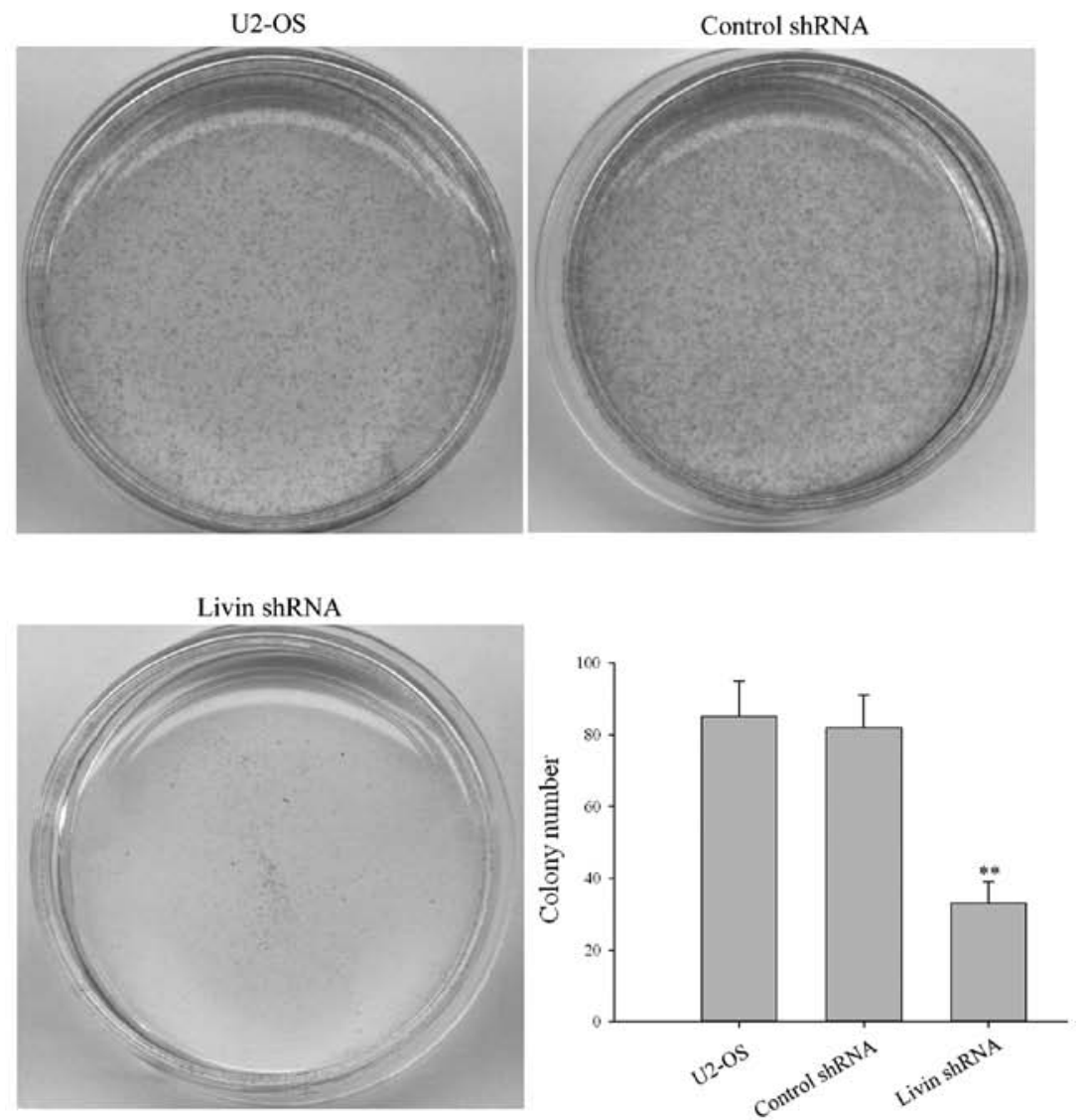

B

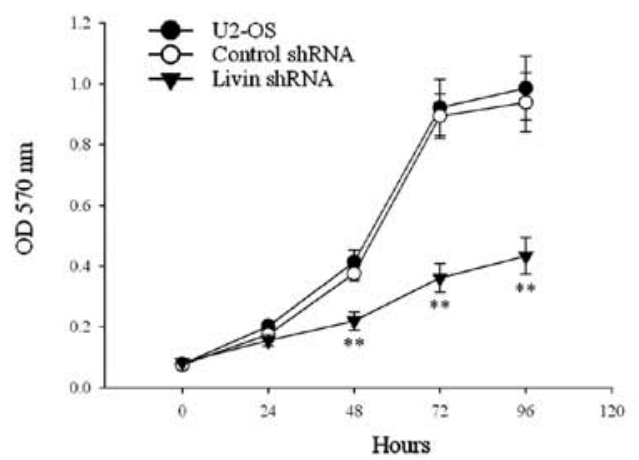

Figure 2. Stable knockdown of Livin inhibited cell proliferation and anchorage-independent growth of U2-OS cells in vitro. (A) In colony formation assay, U2-OS cells were seeded at a density of $2 \times 10^{2}$ cells per $10 \mathrm{~mm}$ dish, and colonies were allowed to grow for 10-14 days. Positive colonies were counted manually. (B) For the MTT assay, U2-OS cells were seeded into 96 -well plates and incubated for different time periods. The experiments were performed in triplicate. ${ }^{* *} \mathrm{P}<0.01$ compared with control shRNA cells.

Stable knockdown of Livin expression enhanced cisplatin cytotoxicity in vitro. Previous studies have documented that depletion of Livin by RNAi increases apoptosis caused by cisplatin in lung (33), gastric (21) and colon (34) cancer cell lines. To test whether knockdown of Livin in U2-OS cells affects their sensitivity to cisplatin, Livin shRNA transfected cells and control cells were treated with $10 \mu \mathrm{g} / \mathrm{ml}$ cisplatin for $24 \mathrm{~h}$ and analyzed for apoptosis by flow cytometry. As indicated in Fig. 6, depletion of Livin in U2-OS cells significantly increased cell death after treatment with cisplatin $(66.61 \pm 9.28 \%)$ compared with control cells $(41.71 \pm 6.55 \%$ and $42.44 \pm 7.13 \%, \mathrm{P}<0.01)$. These findings indicate that Livin plays a crucial role in modulating cisplatin cytotoxicity in vitro.

\section{Discussion}

A retrospective study has shown that high expression of Livin protein in tumor tissues predicts poor survival for patients with osteosarcoma (29), but the potential roles of Livin in osteosarcoma cell growth, migration and drug toxicity have not been investigated. In the present study, we employed a vector-based RNAi strategy to stably silence endogenous Livin expression in U2-OS osteosarcoma cells. Quantitative real-time PCR and western blot analysis confirmed that the pGCsi-H1-Livin shRNA vector was able to dramatically abolish the Livin expression in U2-OS cells. Our further experiments demonstrated that knockdown of 
A
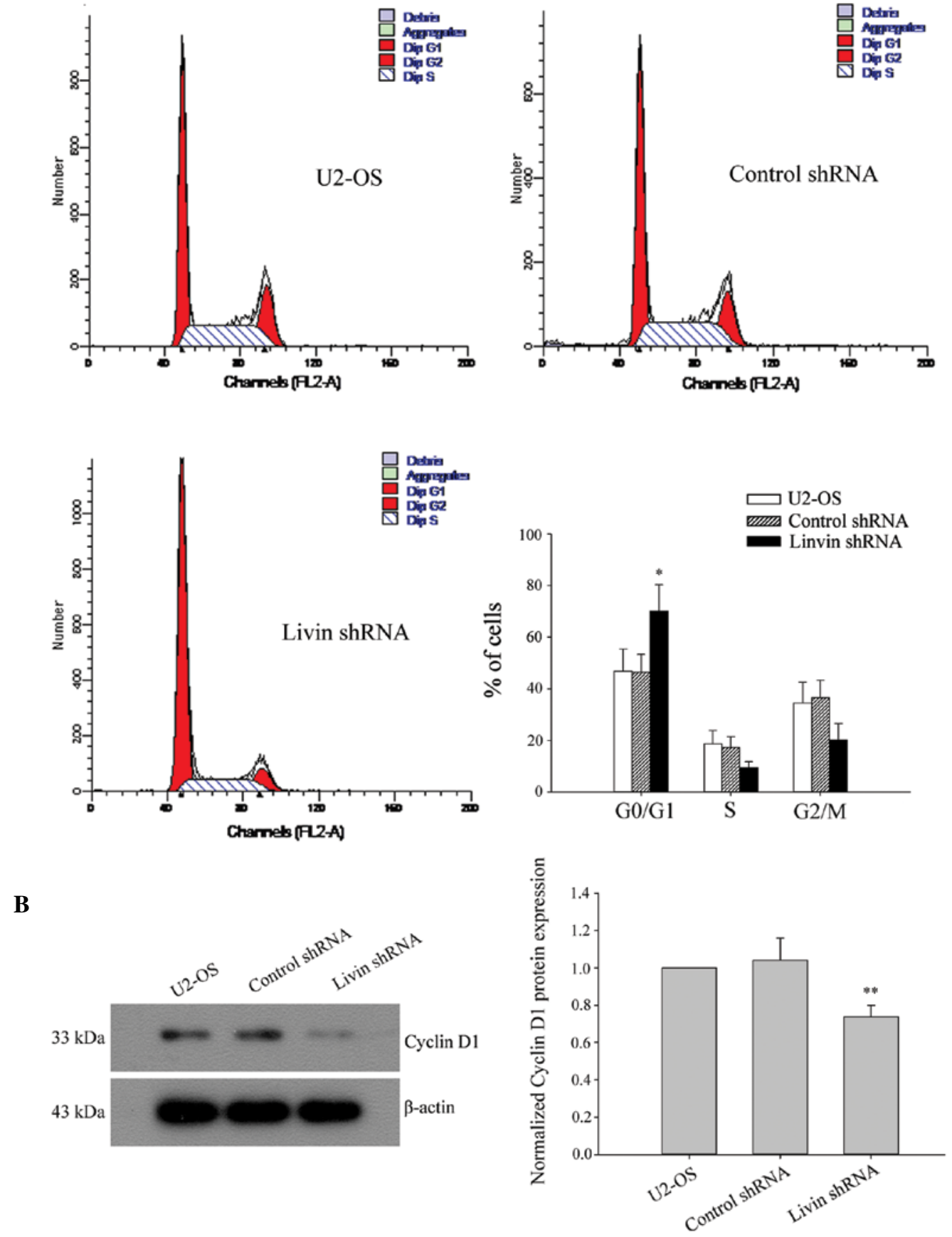

Figure 3. Stable knockdown of Livin induced cell cycle arrest at the G0/G1 phase and downregulated Cyclin D1 in U2-OS cells. (A) Cells at $80 \%$ confluence were stained with PI and quantified for the cycle distribution by flow cytometry. Data are presented as averages from three independent experiments. (B) Western blot analysis of Cyclin D1 protein expression in stably transfected cells. Representative blots are shown, and quantitative data are expressed as the intensity ratio of Cyclin D1 to $\beta$-actin. ${ }^{*} \mathrm{P}<0.05,{ }^{* *} \mathrm{P}<0.01$ compared with control shRNA cells.

Livin in U2-OS cells significantly inhibited cell proliferation and colony formation in vitro. In addition, flow cytometry analysis showed that depletion of Livin reduced the number of cells in the S phase and G2/M phase, while increased the number of cells in the G0/G1 phase, indicating G0/G1 cell cycle arrest. These data are consistent with the published findings in other tumor cells (26,35-37). Cyclin D1 is a key regulator of the G0/G1 to S phase transition. Recently, Chen et al have demonstrated that intratumoral injection of lentivirus-delivered Livin shRNA into SPC-A1 lung cancer xenografts resulted in dramatic silencing of Livin, reduction in tumor growth, and downregulation of Cyclin D1 (38). In this study, our in vitro data consistently indicated that knockdown of Livin in U2-OS cells significantly reduced the expression level of Cyclin D1. Furthermore, it is also reported that knockdown of Livin can induce the cancer cell cycle arrested at the G0/G1 phase and finally lead to apoptosis $(26,35)$. Our present experiments showed that reduced expression of Livin significantly induced apoptotic cell death in U2-OS cells. In corroboration with these results, 
A

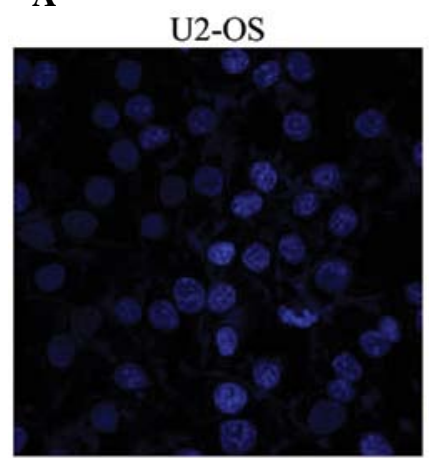

Control shRNA

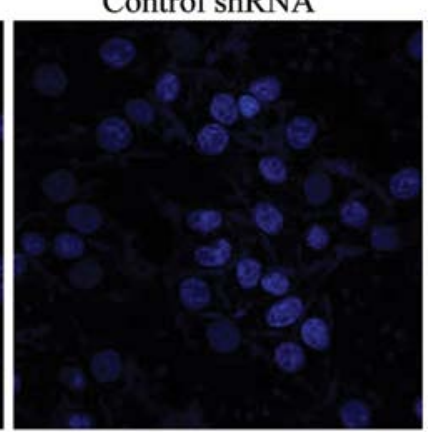

Livin shRNA
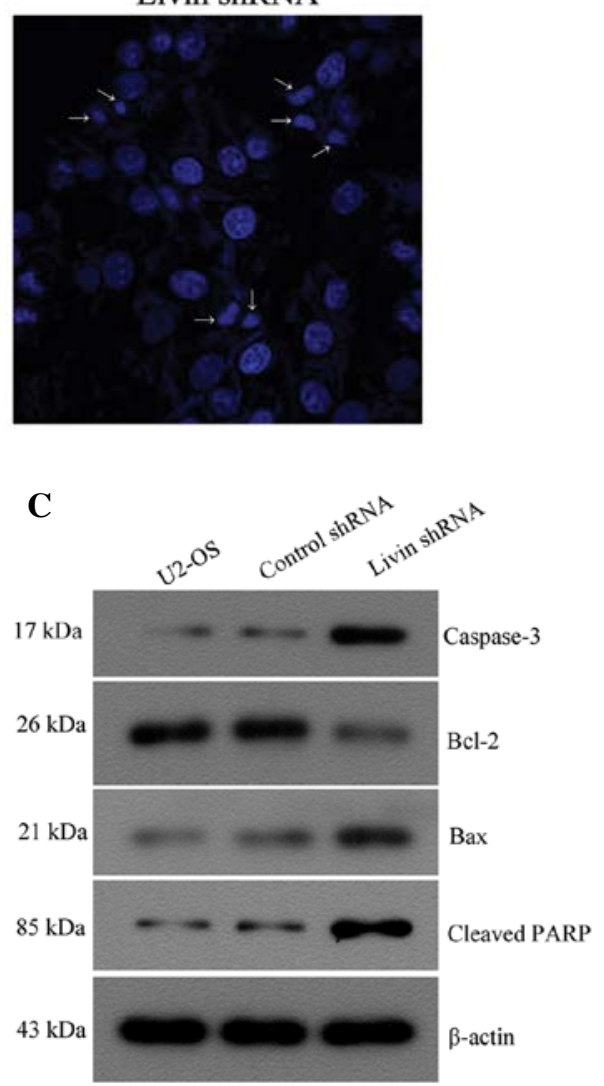

B
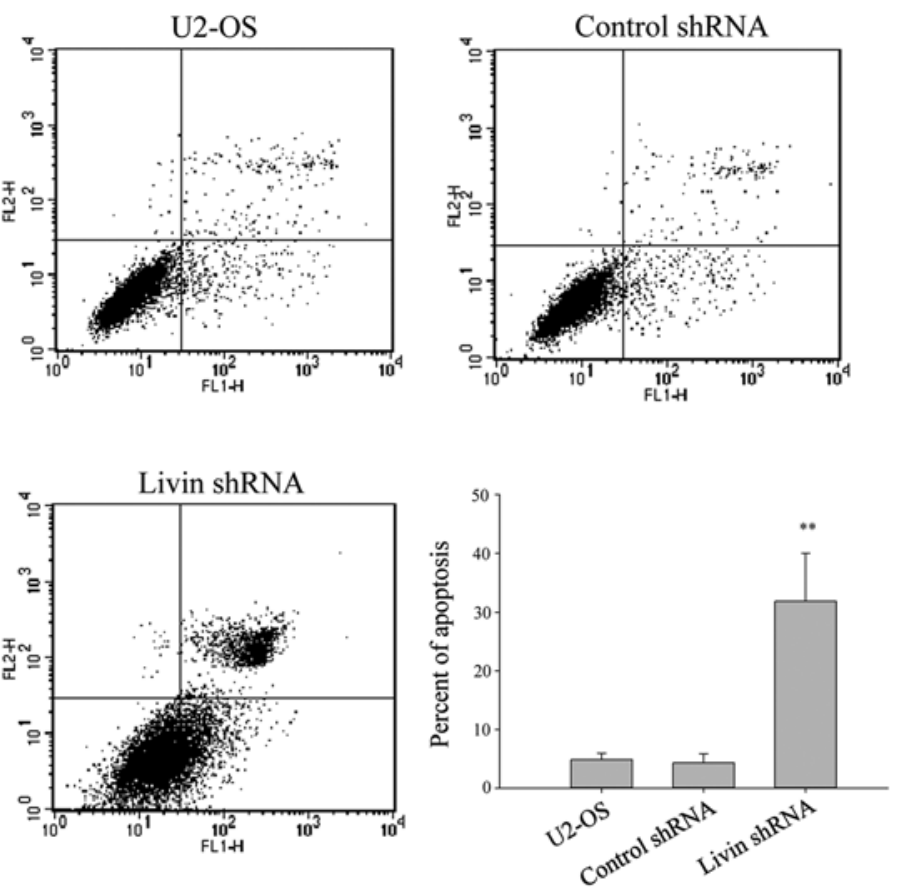

Figure 4. Stable knockdown of Livin induced apoptosis in U2-OS cells. (A) Hoechst 33258 staining showing apoptotic morphological changes in U2-OS cells. Cells were stained with Hoechst 33258 and examined by fluorescence microscopy. Arrows denote typical apoptotic cells. (B) Flow cytometry analysis with Annexin V-PI staining was performed to evaluate the percentage of apoptotic cells. The number of PI/Annexin V single positive and Annexin V/PI double positive cells was calculated as the measurement of apoptotic cells. Data are expressed as means \pm SD. (C) Western blot analysis of activate Caspase-3, Bax, Bcl-2 and cleaved PARP protein levels in U2-OS cells. Densitometric values were normalized by $\beta$-actin. ${ }^{*} \mathrm{P}<0.05,{ }^{* *} \mathrm{P}<0.01$ compared with control shRNA cells.

stably knockdown of Livin resulted in the elevation of activate Caspase-3, Bax and cleaved PARP as well as reduced Bcl-2 levels in U2-OS cells. Taken together, these findings generally support the mechanisms to explain how silencing Livin leads to proliferation inhibition of osteosarcoma cells. Nonetheless, the precise mechanisms by which knockdown of Livin causes cancer cell growth inhibition and cell cycle arrest need to be further elucidated.

Invasive and metastatic capacities are important malignant properties of cancer cells. Several lines of evidence have demonstrated that Livin plays a critical role in acquisition of invasiveness of cancer cells $(27,32)$. In the present study, the wound healing assay and the Transwell invasion assay were conducted to determine the effects of Livin depletion on migration and invasion ability of U2-OS cells. The results showed that knockdown of Livin significantly reduced the invasive and metastatic ability of osteosarcoma cell in vitro. Proteolytic degradation of the basement membrane and extracellular matrix (ECM) by MMPs is an initial step for tumor invasion and metastasis. In particular, MMP-2 and MMP-9 are consistently expressed in malignant tissues and associated increased invasiveness in various cancer cells (39). The present study demonstrated a greater reduction in MMP-2 and MMP-9 protein levels in Livin knockdown $\mathrm{U} 2-\mathrm{OS}$ cells, with parallel results in the wound healing assay and the Transwell invasion assay. Although there is a lack of 
A
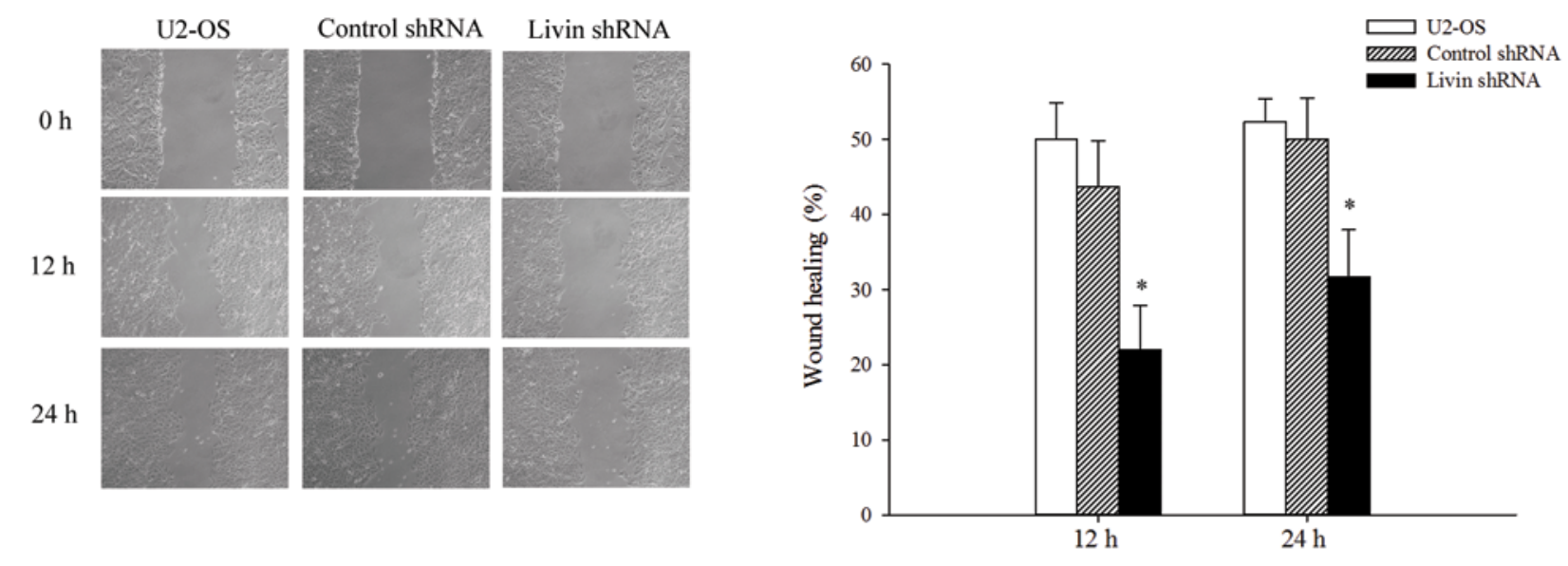

$\mathbf{B}$

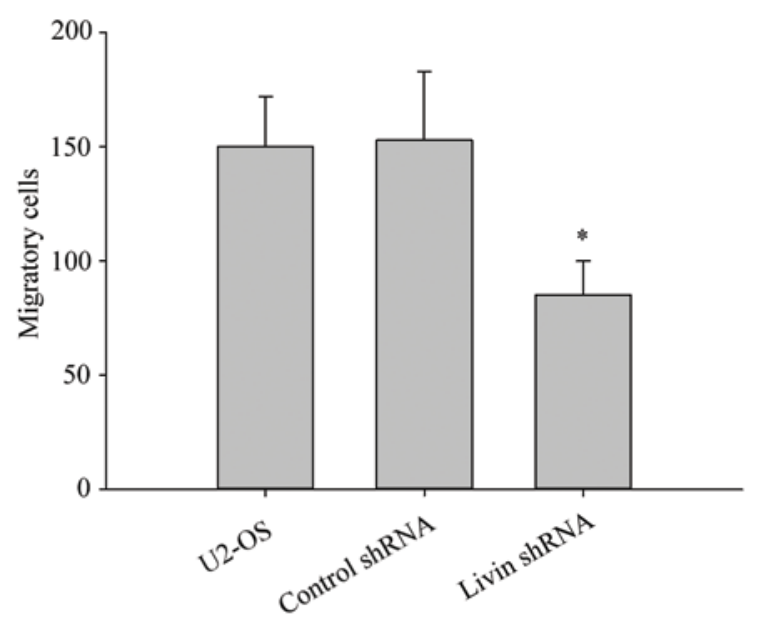

C
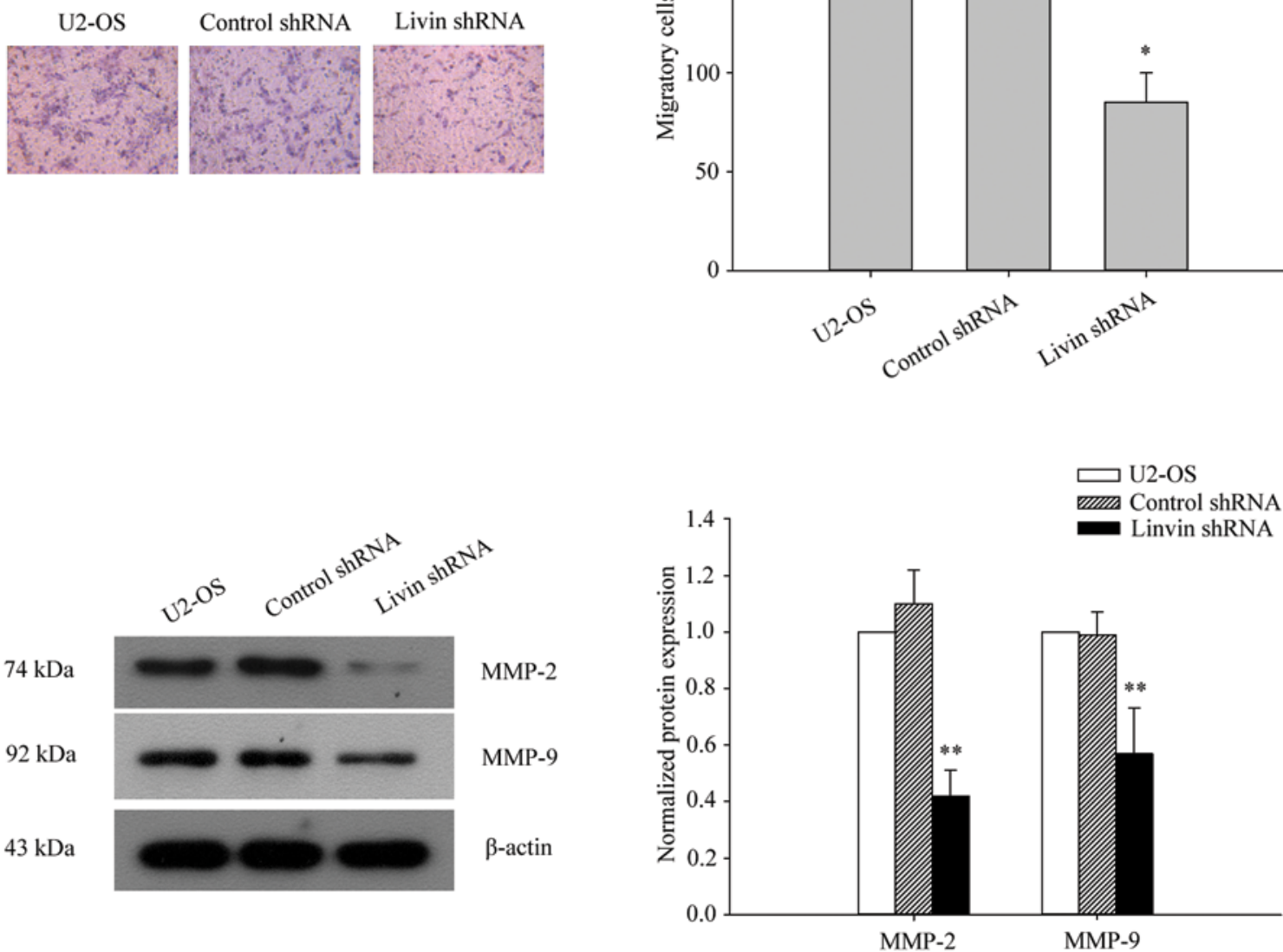

Figure 5. Stable knockdown of Livin suppressed osteosarcoma U2-OS cell migration and invasion in vitro. (A) Wound healing assay of the cell migration. Cell monolayers were scratched with a sterile 200- $\mu$ l pipette tip and images were taken at the indicated time points. Bars represent as the mean percentages of the remaining cell-free area compared with the area of the initial wound. (B) Transwell migration assay of cell invasion. The same number of cells was seeded on the Transwell. After $24 \mathrm{~h}$, the number of cells that had migrated to the lower chamber was counted. Values are expressed as means \pm SD of three independent experiments. (C) Western blot analysis of MMP-2 and MMP-9 protein expression levels in stably transfected cells. The blots shown are representative of three independent experiments. Columns represent means \pm SD. ${ }^{*} \mathrm{P}<0.05,{ }^{* *} \mathrm{P}<0.01$ compared with control shRNA cells.

direct evidence, our data suggest that knockdown of Livin reduces the metastatic ability of osteosarcoma cell by downregulating MMP-2 and MMP-9. Additionally, Livin has been reported to promote prostate cancer cell invasion via the nuclear factor- $\kappa \mathrm{B}$ (NF- $\kappa \mathrm{B})$ signaling pathway $(27,32)$. NF- $\kappa \mathrm{B}$ is a key transcriptional factor for the production of MMP-2 and MMP-9 (40). Therefore, it seems plausible that downregulation of MMP-2 and MMP-9 by Livin knockdown may 

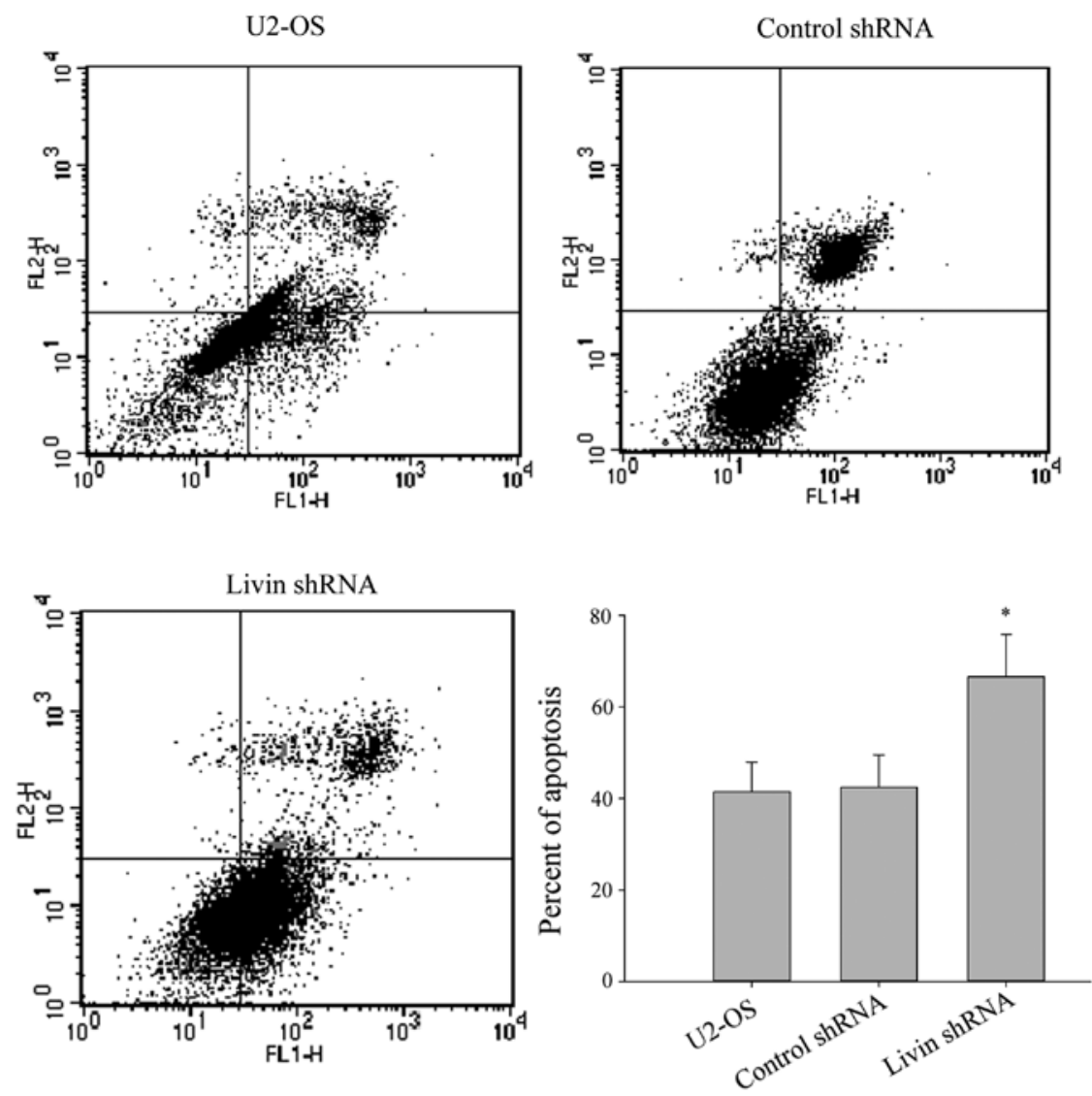

Figure 6. Stable knockdown of Livin increased chemosensitivity to cisplatin in U2-OS cells. Cells were treated with $10 \mu \mathrm{g} / \mathrm{ml}$ cisplatin for $24 \mathrm{~h}$ and analyzed for apoptosis by flow cytometry with Annexin V-PI staining. Bars represent the percentages of apoptosis from three independent experiments. "P $<0.05$ compared with control shRNA cells.

be also mediated via the NF- $\mathrm{KB}$ signaling pathway. However, this assumption requires further investigation.

Cumulative evidence has suggested a novel role of Livin in induction of resistance to various chemotherapeutic drugs, such as cisplatin, vincristine (VCR), etoposide (VP-16) and 5-flourouracil (5-FU) (23,34). Osteosarcoma U2-OS cells are notorious for their resistance to conventional chemotherapeutic regiments (41). To date, however, whether Livin contributes to chemoresistance in osteosarcoma cells has not been investigated. In the current study, we showed that Livin downregulation in U2-OS cells remarkably enhanced apoptosis in response to cisplatin treatment, suggesting that Livin inhibition sensitizes tumor cells with Livin levels that show a high degree of chemoresistance. This is in agreement with previous studies indicating that Livin plays an important role in chemoresistance in various cancer cell lines $(20-21,33)$. Our data, together with previous findings, suggest that targeting of Livin by RNAi combined with chemotherapy provides a potential synergistic therapy for patients with osteosarcoma.

In summary, the present study demonstrated that knockdown of Livin by shRNA effectively inhibited cell growth and invasion, arrested cell cycle at the G0/G1 phase, promoted spontaneous apoptosis, and increased chemosensitivity to cisplatin in osteosarcoma cells. Our findings suggest that Livin may serve as a promising therapeutic target for osteosarcoma.

\section{Acknowledgements}

This study was supported by grants from the National Natural Science Foundation of China (grant nos. 30973021 and 81272946).

\section{References}

1. Ottaviani G and Jaffe N: The epidemiology of osteosarcoma. Cancer Treat Res 152: 3-13, 2009.

2. Chou AJ and Gorlick R: Chemotherapy resistance in osteosarcoma: current challenges and future directions. Expert Rev Anticancer Ther 6: 1075-1085, 2006.

3. Fuchs B and Pritchard DJ: Etiology of osteosarcoma. Clin Orthop Relat Res 397: 40-52, 2002.

4. Akiyama T, Dass CR and Choong PF: Novel therapeutic strategy for osteosarcoma targeting osteoclast differentiation, bone-resorbing activity, and apoptosis pathway. Mol Cancer Ther 7: 3461-3469, 2008 .

5. Salvesen GS and Duckett CS: IAP proteins: blocking the road to death's door. Nat Rev Mol Cell Biol 3: 401-410, 2002.

6. Chang $\mathrm{H}$ and Schimmer AD: Livin/melanoma inhibitor of apoptosis protein as a potential therapeutic target for the treatment of malignancy. Mol Cancer Ther 6: 24-30, 2007.

7. Liston P, Fong WG and Korneluk RG: The inhibitors of apoptosis: there is more to life than $\mathrm{Bcl} 2$. Oncogene 22: 8568-8580, 2003.

8. Nachmias B, Ashhab Y and Ben-Yehuda D: The inhibitor of apoptosis protein family (IAPs): an emerging therapeutic target in cancer. Semin Cancer Biol 14: 231-243, 2004.

9. Schimmer AD: Inhibitor of apoptosis proteins: translating basic knowledge into clinical practice. Cancer Res 64: 7183-7190, 2004. 
10. Gazzaniga P, Gradilone A, Giuliani L, et al: Expression and prognostic significance of LIVIN, SURVIVIN and other apoptosis-related genes in the progression of superficial bladder cancer. Ann Oncol 14: 85-90, 2003.

11. Xi RC, Sheng YR, Chen WH, et al: Expression of survivin and livin predicts early recurrence in non-muscle invasive bladder cancer. J Surg Oncol 107: 550-554, 2013.

12. Tanabe H, Yagihashi A, Tsuji N, Shijubo Y, Abe S and Watanabe N: Expression of survivin mRNA and livin mRNA in non-small-cell lung cancer. Lung Cancer 46: 299-304, 2004.

13. Xiang Y, Yao H, Wang S, et al: Prognostic value of Survivin and Livin in nasopharyngeal carcinoma. Laryngoscope 116 126-130, 2006.

14. Kempkensteffen C, Hinz S, Christoph F, et al: Expression of the apoptosis inhibitor livin in renal cell carcinomas: correlations with pathology and outcome. Tumour Biol 28: 132-138, 2007.

15. Augello C, Caruso L, Maggioni M, et al: Inhibitors of apoptosis proteins (IAPs) expression and their prognostic significance in hepatocellular carcinoma. BMC Cancer 9: 125, 2009.

16. Dasgupta A, Alvarado CS, Xu Z and Findley HW: Expression and functional role of inhibitor-of-apoptosis protein livin (BIRC7) in neuroblastoma. Biochem Biophys Res Commun 400: 53-59, 2010.

17. Xi RC, Biao WS and Gang ZZ: Significant elevation of survivin and livin expression in human colorectal cancer: inverse correlation between expression and overall survival. Onkologie 34: 428-432, 2011

18. Lazar I, Perlman R, Lotem M, Peretz T, Ben-Yehuda D and Kadouri L: The clinical effect of the inhibitor of apopotosis protein livin in melanoma. Oncology 82: 197-204, 2012.

19. Liang YZ, Fang TY, Xu HG and Zhuo ZQ: Expression of CD44v6 and Livin in gastric cancer tissue. Chin Med J (Engl) 125: 3161-3165, 2012.

20. Yu L and Wang Z: Effects of Livin gene RNA interference on apoptosis of cervical cancer HeLa cells and enhanced sensitivity to cisplatin. J Huazhong Univ Sci Technolog Med Sci 29 625-630, 2009

21. Wang TS, Ding QQ, Guo RH, et al: Expression of livin in gastric cancer and induction of apoptosis in SGC-7901 cells by shRNA-mediated silencing of livin gene. Biomed Pharmacother 64: 333-338, 2010.

22. Yang D, Song X, Zhang J, et al: Therapeutic potential of siRNA-mediated combined knockdown of the IAP genes (Livin, XIAP, and Survivin) on human bladder cancer T24 cells. Acta Biochim Biophys Sin (Shanghai) 42: 137-144, 2010.

23. Wang X, Xu J, Ju S, Ni H, Zhu J and Wang H: Livin gene plays a role in drug resistance of colon cancer cells. Clin Biochem 43: $655-660,2010$

24. Yang D, Song X, Zhang J, et al: Suppression of livin gene expression by siRNA leads to growth inhibition and apoptosis induction in human bladder cancer T24 cells. Biosci Biotechnol Biochem 74: 1039-1044, 2010.

25. Liu H, Wang S, Sun H, Pan Z, Zhou W and Wu M: Inhibition of tumorigenesis and invasion of hepatocellular carcinoma by siRNA-mediated silencing of the livin gene. Mol Med Rep 3: 903-907, 2010
26. Yuan B, Ran B, Wang S, Liu Z, Zheng Z and Chen H: siRNA directed against Livin inhibits tumor growth and induces apoptosis in human glioma cells. J Neurooncol 107: 81-87, 2012.

27. Chen F, Yang D, Wang S, et al: Livin regulates prostate cancer cell invasion by impacting the NF-kappaB signaling pathway and the expression of FN and CXCR4. IUBMB Life 64: 274-283, 2012

28. Liu X, Wang A, Gao H, Yuan Z and Jiao Y: Expression and role of the inhibitor of apoptosis protein livin in chemotherapy sensitivity of ovarian carcinoma. Int J Oncol 41: 1021-1028, 2012.

29. Nedelcu T, Kubista B, Koller A, et al: Livin and Bcl-2 expression in high-grade osteosarcoma. J Cancer Res Clin Oncol 134: 237-244, 2008

30. Livak KJ and Schmittgen TD: Analysis of relative gene expression data using real-time quantitative PCR and the 2(-Delta Delta C(T)) method. Methods 25: 402-408, 2001.

31. Li Y, Li X, Fan G, et al: Impairment of p53 acetylation by EWS-Fli1 chimeric protein in Ewing family tumors. Cancer Lett 320: 14-22, 2012.

32. Chen F, Yang D, Che X, et al: Livin mediates tumor cell invasion in the DU-145 cell line via NF-кB. Oncol Rep 27: 2010-2016, 2012.

33. Yuan D, Liu L, Xu H and Gu D: The effects on cell growth and chemosensitivity by livin RNAi in non-small cell lung cancer. Mol Cell Biochem 320: 133-140, 2009.

34. Ding ZY, Liu GH, Olsson B and Sun XF: Upregulation of the antiapoptotic factor Livin contributes to cisplatin resistance in colon cancer cells. Tumour Biol 34: 683-693, 2013.

35. Wang H, Tan SS, Wang XY, et al: Silencing livin gene by siRNA leads to apoptosis induction, cell cycle arrest, and proliferation inhibition in malignant melanoma LiBr cells. Acta Pharmacol Sin 28: 1968-1974, 2007.

36. Wang R, Lin F, Wang X, et al: Silencing Livin gene expression to inhibit proliferation and enhance chemosensitivity in tumor cells. Cancer Gene Ther 15: 402-412, 2008.

37. Ye L, Song X, Li S, et al: Livin-alpha promotes cell proliferation by regulating G1-S cell cycle transition in prostate cancer. Prostate 71: 42-51, 2011

38. Chen YS, Li HR, Miao Y, et al: Local injection of lentivirusdelivered livinshRNA suppresses lung adenocarcinoma growth by inducing a G0/G1 phase cell cycle arrest. Int J Clin Exp Pathol 5: 796-805, 2012.

39. Bauvois B: New facets of matrix metalloproteinases MMP-2 and MMP-9 as cell surface transducers: outside-in signaling and relationship to tumor progression. Biochim Biophys Acta 1825: 29-36, 2012

40. Tabruyn SP and Griffioen AW: A new role for NF-kappaB in angiogenesis inhibition. Cell Death Differ 14: 1393-1397, 2007.

41. Ma D, Tremblay P, Mahngar K, Collins J, Hudlicky T and Pandey S: Selective cytotoxicity against human osteosarcoma cells by a novel synthetic C-1 analogue of 7-deoxypancratistatin is potentiated by curcumin. PLoS One 6: e28780, 2011. 